\title{
Psychiatry: a core curriculum for undergraduate medical students
}

\author{
Mervat Nasser
}

\begin{abstract}
There is a growing pressure on universilies to reviow their curriculum for undergraduate medical students in the Ilght of the new General Medical Councll (GMC) Education Committee recommendations (1993). One major recommendation was for universtiles to develop a 'core curriculum' for every medical discipline. In poychlatry, the cumiculum for undergraduate medical students has always varied between universities. We propose a broad design of a core curriculum that consists of elght modules covering what is considered vital to the subject and relevant to the student's future medical practice. The cumiculum is designed to be tought in pre-clinical as well as clinical years in an attempt to achieve full integration and aspires to succeed in eliminating this traditional divide.
\end{abstract}

The enquiring mind will survive, the mind filled with detail or dogma, to the exclusion of thought or reflection will fail to adjust." (General Medical Council, 1987)

The planners of any psychiatric curriculum for undergraduate medical students are aware that the great majority of medical students will not pursue a career in psychiatry and that the only knowledge they will acquire about psychiatry, probably for the rest of their medical life, will be that taught in undergraduate education. Planners should therefore ensure that the content of the course is sufficient to help students make informed career choices. Myths should be dispelled about the scientific standing of psychiatry, the assumed dangerousness and untreatability of mental illness, and the nature of available methods of treatment, such as involuntary hospitalisation and the use of electroconvulstve therapy, which are perceived as barbaric.

Psychiatry has a responsibility to provide a holistic approach to clinical problems and promoting psychological mindedness.

The main contribution of psychiatry to medicine is its attempt to understand the notion of health and disease. Is disease a form of suffering, a demonstrable pathological lesion, a biological disadvantage or a statistically defined state? Psychiatry is forced to examine these issues in order to protect against the unnecessary medicalisation of human behaviour. This poses particular difficulties to students who enter medical faculties with an attitude of certainty about the nature of disease and its causality. The teacher of psychiatry therefore should address the multifactorial nature of disease determination - biological, social and psychological - and foster broad mindedness. He should challenge dogma and give students the opportunity to think and more importantly tolerate doubt and impermanent facts, "It would be discreditable if psychiatrists were huddled up at either extremes... wholly engaged in guessing or ignorantly certain...." (Lewis, 1947).

\section{Psychiatry in the undergraduate medical curriculum in the UK}

Psychiatry constitutes an established part in all undergraduate medical curricula in the UK. There is no single system that applies to all universities and there are considerable variations between universities as to the length of the course, its contents and the style of teaching. Most universities regard behavioural sciences and medical sociology courses as part of a basic sciences course and these are introduced in the pre-clinical years. Clinical skills in psychiatry, however, are only introduced in the course of the clinical years. In a minority of cases, such as Southampton and Newcastle, clinical work is introduced early in the curriculum as the philosophy of these universities is based on full integration between clinical and basic sciences. Teaching takes the form of organised lectures, seminars or small groups. This is in addition to a period of attachment to a clinical firm where the students have immediate exposure to clinical material and are expected, through case presentation, to develop history taking, diagnostic and formulation skills. In teaching the students communication skills, the teacher takes advantage of live interviews, role-play or pre-recorded videotapes. The students' assessments are carried out by clinical and written examinations.

It is difficult to describe these various courses in detail or discuss their assets or weaknesses, but it is important nonetheless to acknowledge that all university medical undergraduate 
courses are currently undergoing major changes in the light of the GMC Education Committee recommendations issued in 1993. According to Crisp (1994) “... our discipline has an opportunity to re-evaluate its potential contributions, both in 'core' and 'selective' terms".

The GMC (1993) recommended a decrease in the emphasis put on factual learning and an enhancement of the student's scope towards self directed learning. It also discouraged didactic instruction, and viewed teaching as a means of introducing the student to new ways of thinking. The art of teaching should be interactive and the teacher should employ modern educational methods. The most important recommendation, however, was for every medical speciality to establish a core curriculum which is systembased, with integration of teaching in clinical and basic sciences and the elimination of the preclinical/clinical divide (Sensky, 1994).

\section{A suggested core curriculum}

The curriculum proposed here has elements in common with many ongoing undergraduate preclinical and clinical courses and shares many of the objectives outlined in Crisp's paper. However, the main purpose is to present one course that integrates the contents of both pre-clinical and clinical courses. It consists of eight modules, the first five deal with the major issue of assessment, including sources and methods of eliciting information. The other three include diagnostic/ management formulation, prescribing skills and ethical/legal aspects.

The issues of what modules ought to be taught in pre-clinical or clinical years, the curricular time table and the method of teaching are beyond the scope of this article.

\section{The modules}

\section{Communication skills}

Interview in psychiatry is par excellence the main investigative method. The principal aim of this module therefore is to train the students to communicate sensitively and effectively with the patient. The key task in any clinical interview is to obtain an accurate history of the patient's problem. Students are encouraged to use a set of established guidelines to perform the interview successfully; these should cover in a systematic manner the nature of the problem, time, course and precipitating factors. The interviewer should obtain information about the patient's background, including family, personal history, past medical and psychiatric history, as well as premorbid personality. A mental state examination should then be carried out. The interviewer should use open ended questions, particularly in the early part of the interview, followed by more specific probes. Questions presupposing an answer or limiting the information given should be avoided and appropriate language should be employed to particular audiences.

The skilful interview also constitutes an integral part of the therapeutic process. Students should be taught the effective use of verbal and non-verbal clues and how to respond to emotionally charged situations. They should show empathy and have an unconditional regard for patients and their carers (Maguire et al, 1986).

Attention should be given to learning how to communicate with children, as this is often a recognised weakness among medical students. Time factors prevent teaching child psychiatry to undergraduate students and this module should be used to help the student gain skills in assessing the child and the family (Pearce \& Nicol, 1989).

Teaching communication skills is also important outside the realm of the doctor-patient relationship in helping young doctors to communicate better with colleagues and other professionals. This is relevant to their working later in a multidisciplinary team. These skills should also improve their performance and chances in job interviews.

Communication skills are not limited to oral skills, they should extend to teaching written skills with reference to ability to organise data in an appropriate sequence, abstract relevant issues and focus on the main clinical problem as a prerequisite to making a clinical judgement.

\section{Assessment of mental phenomena}

This module follows on from the first one; the student is introduced to the doctrine of descriptive psychopathology as a means of understanding mental phenomena. In this way such phenomena as delusions, hallucinations, compulsive phenomena, overvalued ideas and the different modes of personal awareness are defined and discussed. The range of phenomenological definitions is associated with an understanding of the difference between objective (demonstrable) and subjective (graspable) experiences. Students should be able to distinguish between form and content in psychiatry, the 'form' of the phenomenon taking precedence over its 'content'.

An important aspect of the diagnostic method is the detection of morbidity, particularly if this is subtle and merges with normality. This is applicable to the area of depression, where the question commonly asked is "when does unhappiness become depression?" The delineation between the normal and the morbid is largely determined by the criterion of functioning and the common view that the diagnosis of depression is made if biological functions are depressed. 
The student should also learn how to assess risks unique to psychiatry, like suicide, violence to others and self-neglect.

\section{Behavioural sciences - personality/ cognition/emotions}

The objective of this module is to enable students to have an understanding of the concept of conditioning, classical, operant and modelling, and their impact on modifying human behaviour and the treatment of neurosis. Theories of personality development introduce the students to psychodynamic principles and the different coping and defence mechanims. Aspects of learning, intelligence and memory and their clinical application are included in this part of the course. Students should also develop an understanding of the concept of stress and its psychophysiological models and the nature of addictive behaviours.

\section{Psychiatry and general medicine}

This module tackles the issue of the interface between general medicine, general practice and psychiatry and offers some understanding of those individuals who present with physical symptoms as a manifestation of psychological problems, or psychological problems as a manifestation of physical conditions. Students should learn about the psychological aspects of neurological disease and organic confusional/delirious states, particularly those that follow brain pathology, organ failure, fevers and toxic conditions. They should learn about the psychological contribution to postnatal pathology, menstrual problems and the psychological aspects of abortion and hysterectomy. Special emphasis should be given to the psychogenesis of pain and the psychological sequelae of chronic physical problems including disability and issues connected with litigation. They should be taught about factors that influence the development of somatisation with reference to abnormal illness behaviours and the adoption of the 'sick role'.

\section{Psychiatry and social reality}

It is difficult to imagine teaching psychiatry outside the context of existing social realities. Knowledge of the role of social variables in producing psychopathology is essential. Areas of importance are loss, life events, supporting relationships, unemployment, social class, gender, race, culture, ethnicity and political intolerance. Students should be encouraged to question stereotyped assumptions about normality and identify links between family types and the psychological health of individual and family.

Students should be made aware of the stigmatising nature of mental illness and the impact of labelling and institutionalistion, and be introduced to social methods of treatment and the concepts of community care.

\section{Formulation skills - making sense of clinical data}

Clinical formulation is a detailed clinical evaluation of the patient, including assessment, management and prognosis, made on the basis of the clinical data obtained from the patient's history and mental state examination. Students should be taught that diagnostic entities are not mutually exclusive and that diagnosis is the subject of continued review in the light of emerging evidence. Students need to be introduced to the value of classification in diagnosis (Kendell, 1975); limitations of the categorical and dimensional approaches to classification should be discussed as well as the basis on which the existing classification systems (ICD-10 (World Health Organization, 1992) and DSM-IV (American Psychiatric Association, 1994)) have evolved.

Aetiological formulation uses the diathesisstress model which incorporates biological, psychological and social factors.

Management formulation includes both investigation and treatment, and requires proper assessment of the patient's 'symptom pattern' and degree of distress. Students should have an adequate knowledge of psychopharmacology and other available therapeutic options. The patient's prognosis is determined by a number of factors including premorbid adjustment and the degree of social and family support.

Formulation therefore is different from case summary as it involves more than a statement of the basic diagnosis and requires considerable thought and analysis. The skills involved in teaching the psychiatric formulation are highly relevant to all aspects of clinical medicine.

\section{Prescribing skills}

Prescribing should be scientifically based with clear indications. The students should acquire the ability to balance the benefits of drugs against possible risks. Special attention should be given to the existence of more than one medical problem and possible drug interaction, with emphasis on the judicious use of the full potential of individual drugs to prevent polypharmacy.

Other rules include the choice of a particular drug among the growing list of new antidepressants. Dose, duration and cost effectiveness need to be discussed.

The general climate of opinion is an important aspect in psychiatry as cultural views on what constitutes good psychiatric practice may be at variance with scienfitic reality. Medical students for instance come to psychiatry with the view that 
psychopharmacology and psychotherapy are contradictory and commonly favour the latter. Gaining insight into the importance of medication, particularly for severe and enduring mental illness, is paramount.

Students should be made aware of the differences between short- and long-term medication and the risks involved in hospital and community prescribing, particularly the risk of fatal overdosing, and the need for continuous monitoring of certain medications, like injectable depots and lithium.

An understanding of the significance of the patient's level of reliability and compliance with prescribed medication should be aquired which could be determined by the impact of this medication on his work, domestic life and fitness to drive.

\section{Philosophy - ethical and legal issues}

There is a growing realisation of the need to deal with ethical issues in a systematic way in all undergraduate medical courses. Students need to have at least an elementary introduction to the philosophy of science, theory of knowledge and ethical reasoning. Issues of the individual's autonomy, choices and consent versus the psychiatrist's paternalistic tendencies, need to be addressed. This ethical position is strongly related to legal issues concerning mental health law with reference to compulsory hospitalisation and involuntary treatment. Students should become aware of the patient's basic human rights and the potential weakness in psychiatry to be manipulated by social forces and possibly abused for political reasons.

\section{Conclusion}

A new core curriculum in psychiatry for undergraduate medical students is proposed which stretches over pre-clinical and clinical years. It is described in broad terms with emphasis on content rather than organisational factors or methods of administration and has the objective of fulfilling some aspects of the GMC recommendations of an integrated and relevant model of teaching.

However, the GMC Education Committee also recommended that any core curriculum should be augmented by special study modules allowing the students to study, in depth, areas of particular interest to them. This should alert planners to the importance that needs to be given to whatever opportunities currently exist for students in this respect. Examples of such opportunities are the Southampton Fourth Year Project and the BSc intercalated degree which is available in the Leeds and Leicester Schools of Medicine. These two models offer students a greater learning experience and aspire to achieve the desired objective of making the undergraduate course less vocational and truly educational (Mindham, 1989).

Undergraduate medical education has always been the subject of continued discussion and the fever of these debates is now likely to escalate in the light of the GMC demand for change. There is a need for those engaged in teaching, and concerned with it, to express their views.

\section{References}

AMERICAN PSYCHIATRIC Assocation (1994) Dlagnostic and Statistical Manual of Mental Disorders (4th edn) (DSMIV). Washington, DC: APA

CRISP. A. H. (1994) Psychiatric contributions to the undergraduate medical curriculum. Psychiatric Bulletin, 18, 257-259.

General Medical CouncIL (1993) Tomorrow's Doctors: Recommendations on Undergraduate Medical Education. London: GMC.

Kendeu, R. E. (1975) The Role of Diagnosis in Psychiatry. Oxford: Blackwell Scientific Publications.

LEWIS, A. (1947) The education of psychlatrists. Lancet, th, 79-83.

MAgUIRE, P. FAIRBURN, S. \& FLETCHER, C. (1986) Consultation skdlls of young doctors. British Medical Journal, 292. 1573-1578.

MnNDHAM, R. H. (1989) Undergraduate medical education in Britain, a time for change? Newsletter of the Association of University Teachers of Psychiatry. 35-39.

PEARCE, J. \& NiCHOL, A. R. (1989) Teaching child psychiatry to medical students using limited resources. Newsletter of the Association of Universtity Teachers of Psychiatry. 5-9.

SENSKY. T. (1994) The place of the psychiatrist in the new undergraduate curriculum. Psychiatric Bulletin. 18. 557-559.

WORLD HEALTH ORGANIZATION (1992) The Tenth Revision of International Classification of Diseases and Related Health Problems (ICD-10). Geneva: WHO.

Mervat Nasser, Consultant Psychiatrist/Senior Lecturer, Department of Psychiatry, University of Leicester; and Robert Kilpatrick, Clinical Sciences Building, Leicester Royal Infirmary, PO Box 65, Leicester LE2 7LX 